\title{
Sterile Stuhltransplantate gegen Colitis
}

\author{
Die Transplantation von Stuhl hat die Therapie der pseudomembranösen Colitis revolutioniert. \\ Eine Pilotstudie deutet jetzt an, dass die Übertragung von sterilem Stuhl ausreichen könnte.
}

_ Die Transplantation von Spenderstuhl kuriert bis zu 100\% der Patienten mit auf einer Clostridium-difficile-Infektion (CDI) beruhenden pseudomembranösen Colitis [Gastroenterology. 2015;149:223-37]. Das gesunde Mikrobiom des Spenders verbessert die intestinale Dysbiose des Patienten. Allerdings birgt die Übertragung unbestimmter Mengen und Arten lebender Bakterien Risiken für infektiöse, metabolische und maligne Erkrankungen für den Stuhlempfänger [Nat Rev Gastroenterol Hepatol. 2016;13:508-16].

In einer Pilotstudie an fünf Patienten mit CDI-assoziierter Colitis wurde nun getestet, ob schon der Transfer von Stuhlflüssigkeit, die Zellschutt, DNAFragmente und Protein enthält, aber keine lebenden Mikroorganismen, zu einer Besserung führt. Dafür wurden ca. $50 \mathrm{~g}$ aufgearbeiteter Spenderstuhl steril filtriert, um alle lebenden Bakterien zu entfernen. Die hellbraune, klare Flüssigkeit wurde den Patienten einmalig via Nasojejunalsonde appliziert.
Stuhlproben der Empfänger wurden vor dem Transfer sowie eine Woche und sechs Wochen danach untersucht. Mikrobiom-, Virom- und Proteomprofile der Spender und Empfänger wurden verglichen. Die Patienten wurden 6-33 Monate lang nachbeobachtet.

Zwei bis vier Tage nach dem Steriltransfer zeigte sich eine klare klinische Besserung. Alle Symptome der CDI-Colitis wurden für mindestens sechs Monate eliminiert. Stuhlgang und Gewicht der Patienten normalisierten sich. Alle Patienten konnten einen Tag nach der Behandlung entlassen werden.

Die Stuhlanalysen zeigten Veränderungen der mikrobiologischen und virologischen Zusammensetzung. In der sterilen Stuhlflüssigkeit fanden sich allerdings zunächst keine speziellen Proteinkandidaten, die mit dem therapeutischen Effekt in Zusammenhang gebracht werden konnten.

- Ott SJ, Waetzig GH, Rehman A et al. Efficacy of sterile fecal filtrate transfer for treating patients with Clostridium difficile infection. Gastroenterology. 2017;152:799-811
Die wässrige, sterile Lösung wird via Nasojejunalsonde appliziert.

\section{KOMMENTAR}

Das Ergebnis dieser kleinen, aber äußert interessanten Pilotstudie deutet darauf hin, dass viele der therapeutischen Effekte eines Stuhltransfers durch bakterielle DNA-Fragmente, Metabolite oder Bakteriophagen vermittelt werden könnten. Die sterile Stuhltransplantation könnte gerade bei immuninsuffizienten Patienten eine Therapiealternative sein. Sie lässt sich auch sehr viel besser standardisieren als der herkömmliche Stuhltransfer, mit dem sie zeitnah in größeren Studien verglichen werden sollte.

PD Dr. med.C. H. Waggershauser

\section{Hier steht eine Anzeige.}

\author{
Springer
}

